\title{
TURISMO Y CULTURA EN PAÍSES EN VÍAS DE DESARROLLO ${ }^{1}$
}

\author{
Oswaldo Lorenzo Quiles² \\ Tomás López-Guzmán Guzmán ${ }^{3}$ \\ María del Carmen Burgos Goye ${ }^{4}$
}

\begin{abstract}
This is an exciting time for international cultural tourism. The tourism industry is moving away from the traditional sun, sand and food and towards a huge range of potential and actual attractions that will appeal to the global tourist. These assets provide a valuable resource for developing countries.
\end{abstract}

Keywords: cultural tourism; developing countries; social consumption; habits; globalization

Resumen: Es este un momento ciertamente efervescente en materia de turismo cultural en el ámbito internacional. La evolución propia del sector turístico hacia el aprovechamiento de otros activos y recursos distintos y/o complementarios a los tradicionales de sol, playa y gastronomía deviene hoy en un vasto compendio de elementos que en potencia y de hecho discurren por cauces de aprovechamiento más globales, en cuanto a la amplitud del espectro de anhelos de consumo por parte del turista y su localización geográfica dispersa. Asimismo, estos activos del sector suponen un valioso recurso de aprovechamiento para aquellos países con una situación de desarrollo no consolidado.

Palabras clave: turismo cultural; países en vías de desarrollo; hábitos de consumo social; globalización

Al interesante y creciente binomio turismo-cultura hay que sumar en la actualidad, casi obligatoriamente, innegables relaciones de doble vínculo con otro fenómeno que cobra interés en aumento por sus posibilidades de contribución a una preocupación constante entre la comunidad internacional, la de la mejora de las condiciones de vida, de desarrollo humano, económico, cultural y social en los países en vías de desarrollo. Este nuevo ámbito turístico está claramente ligado a lo que común y socialmente se conoce por cultura, entendida ésta en su sentido más ecléctico y contemporáneo, es decir, calificada como un vasto mosaico de actividades y producciones materiales e inmateriales genuinamente humanas (Lorenzo, 2001).

Lorenzo Quiles, O.; López-Guzmán Guzmán, T.; Burgos Goye, $M^{a}$ del C. (2012). Turismo y cultura en países en vías de desarrollo. DEDiCA. REVISTA DE EDUCAÇÃO E HUMANIDADES, 3 (2012) março, 103-112 


\section{La necesidad cultural del turismo actual}

El sector turístico internacional ha empleado como reclamo desde hace décadas los atractivos que para el viajero suponían esas condiciones y escenarios de descanso pasivo que ofrecen en sí mismos los lugares geográficos con condiciones naturales marítimo-costeras y de temperaturas medias-altas, especialmente durante la estación estival. Los años setenta y ochenta son un claro referente de este hecho.

El modelo de vida impuesto a través de los medios de comunicación durante este tiempo atrás y difundido ampliamente entre gran parte de los países más desarrollados e industrializados, modelo proveniente de las construcciones sociales norteamericanas y claramente orientado hacia el consumismo fácil y el disfrute de lo inmediato, propugnaba un uso del tiempo libre y de ocio sólo productivo en términos de descanso y reposo diurno del cuerpo y la mente y ocupación lúdico-festiva durante la noche. De forma manifiesta e indiscutible, un sin fin de generaciones asentadas en el occidente rico demandaba este tipo de turismo como el más alto horizonte personal y familiar de supuesto descanso vacacional al que se podía aspirar y también como ostentación "necesaria" entre los círculos sociales inmediatos de una economía y estatus delimitado entre los estratos solventes.

En España, por ejemplo, este modelo turístico se vivía hasta casi los años noventa principalmente desde dos frentes. Por un lado, numerosos pueblos costeros españoles aumentaban espectacularmente su población veraniega con la llegada de turistas sobre todo franceses, alemanes e ingleses, que venían buscando en sus estancias de larga o corta duración el placer de las playas soleadas y los tópicos de la cocina española. Sin duda, esta penetración estacional de viajeros europeos procuraba una entrada de divisa muy esperada por los lugareños que en ocasiones daba patente de corso a los turistas para justificar comportamientos y actitudes difícilmente tolerables en sus países de origen.

Por otra parte, encontramos los turistas españoles que desde el interior del país también se desplazaban hacia la costa en verano buscando los mismos atractivos que sus homólogos extranjeros, aunque con un mayor recato en las costumbres y las formas de uso social e igualmente una menor capacidad de gasto y poder adquisitivo en sus vacaciones.

Huelga decir que raro era el ciudadano español medio en estos años con posibilidades económicas para permitirse viajes 
turísticos al extranjero, aunque se tratase de países europeos cercanos.

Este escenario español de flujos y perfiles turísticos permite su extrapolación a muy diversos lugares del mundo, por cuanto representa no sólo la esencia del modelo de consumo de activos ofrecidos por el turismo de las décadas en cuestión, sino también la eterna diferencia de posibilidades con que siempre han contado y cuentan los viajeros de los países más y menos ricos, que determina un turismo transnacional repleto de opciones y complementos de disfrute para los primeros y sólo de interior y modesto para los segundos. Además, queda fuera de toda duda que España ha trazado uno de los caminos principales a seguir para el turismo internacional, como lo demuestra el hecho que en este momento sea el segundo destino turístico mundial, después de Francia, con casi 53 millones de turistas anuales en 2010 (Ministerio de Industria, Turismo y Comercio, 2011).

La industria turística, durante estas décadas anteriores a los noventa, basaba fundamentalmente su juego de oferta-demanda con el cliente en el escaparate expuesto de sol marítimo y gastronomía, vendiendo un expositor de productos que trataban de trasladar al viajero a un entorno que, aunque muy de lejos, emulaba los referentes máximos de la fantasía turística más explotada, la del paraíso tropical, caribeño y exótico.

Si bien los países europeos más ricos contaban ya entonces con cierta tradición de un turismo cultural todavía mayoritariamente alternativo -un turismo de acercamiento y conocimiento más profundo hacia los bienes patrimoniales del lugar de llegada del turista con tradición histórica, artística y monumental-, el acicate del turismo de playa resultaba más acorde al modelo de sociedad consumista de bienes y servicios inmediatos y poco comprometida con el entorno, su conservación y perdurabilidad. Incluso sociológicamente podríamos establecer una relación directa entre este tipo de turismo y la superficialidad que aflora de forma común en la exhibición gratuita del cuerpo en las playas, sea para ver o ser visto, y que nutre uno de los tópicos que ha utilizado durante años y sin ambages el marketing del sector: el goce sensual y atractivo de la visión del cuerpo femenino y masculino asociado al producto, al lugar de destino para el viajero.

Ya en fechas recientes, el cambio social sobrevenido desde finales de los años ochenta paralelamente a la emergencia del concepto internacionalizante de globalización (AA. VV., 2006) no 
sólo ha traído consigo una nueva concepción de la economía, la sociedad y los países en vías de desarrollo. Encontramos también un despertar social amplio, en el plano internacional, de los intereses individuales y colectivos hacia otros valores tangibles e intangibles distintos de los habituales de disfrute meramente consumista y hedonista y que indefectiblemente se traslada a las demandas turísticas, nos estamos refiriendo a los valores culturales.

La cultura está cada vez más presente entre los hábitos de consumo de los ciudadanos medios en los países industrializados (AA. VV. 1999; SGAE, 2000), habiéndose convertido ya ésta en el atractivo primero de la oferta de la mayor parte de los paquetes y productos de la industria turística, pues qué es la experiencia de un turista si no una experiencia fundamentalmente cultural (Venturini, 2005).

Como se ha ido exponiendo, no ha sido casual este cambio. Por el contrario, la diferente orientación de los agentes empresariales del sector turístico responde claramente a las nuevas demandas surgidas entre la población, que a su vez son heredadas del cambio de paradigma social imperante en los principales países del mundo y que toma ahora un rumbo global hacia el compromiso con el entorno natural, patrimonial y humano, en coherencia con el nuevo marco de lo sostenible que, a pesar de lo que pueda tener de moda introducida masivamente por los medios de comunicación, impregna muchos de los discursos políticos e intelectuales claves para entender el mundo actual y que han acabado extendiéndose tanto entre las clases dirigentes como medias y populares.

Naturalmente, la industria del turismo no siempre busca en la cultura un horizonte hacia el que volcar su posible solidaridad, pues en el ánimo de numerosas empresas turísticas sigue estando el lucro de sus accionistas e inversores, pero sí hay que reconocer que en este emergente cruce de intereses entre turismo y cultura aparece un fenómeno muy positivo para la segunda. La puesta en valor de los activos culturales como motores de llamada o reclamo turístico y vía de ingresos sustanciales de divisa para cualquier país convierte a estos activos en instrumento potencial de desarrollo de pueblos y ciudades, lo que ha llevado a Gobiernos y Administraciones Públicas de muchos países a tomar conciencia de ello y presionar al sector para que la riqueza generada por la explotación de los recursos culturales no se circunscriba sólo al ámbito de lo privado, sino que revierta igualmente a la población autóctona en términos tanto económicos como de creación de 
riqueza social mediante la generación de empleo, la conservación del patrimonio o la recuperación del entorno natural y humano. En definitiva, para que esta riqueza contribuya de manera significativa a la creación de un mejor estado de bienestar de los lugares turísticos -que en potencia son todos los países- menos desarrollados.

\section{Turismo cultural como vehículo de desarrollo}

La valoración de la cultura como cauce de mejora de condiciones de vida de un lugar geográfico y su comunidad humana es especialmente interesante, por su potencial de inducir riqueza añadida al capital circulante proveniente de divisas turísticas (LópezGuzmán, Lorenzo y Serrano, 2005), para ser aplicada a países en vías de desarrollo, considerados éstos en un alto número en función de diferentes indicadores tomados por el Banco Mundial y que concreta en 118 la Lista de la Unión Internacional de Abogados (UIA) de Países en Vías de Desarrollo, lista elaborada en el año 2002 (UIA, 2006).

Bajo este nuevo prisma de aprovechamiento y optimización de los recursos culturales por el turismo como fuente de riqueza en países con economías débiles y/o emergentes, como Cuba o Marruecos, por citar dos ejemplos de países distantes geográficamente entre sí pero cercanos en muchos de sus problemas estructurales de bienestar de sus pueblos, la cultura adquiere una dimensión alejada de las consideraciones y visiones convencionales, presentándose como un modo característico de vida de los habitantes de un lugar y el concepto de desarrollo como un conjunto creciente de opciones de existencia antes que como un vehículo sólo de producción material (Fukuda, 2001; Serrano, Lorenzo y López-Guzmán, 2005). Más aún, la cultura es calificada "desde dentro" por analistas sociales de estos países como elemento indispensable para el desarrollo, reflexión que hacía en 2005 un periodista de El Salvador (Rivas, 2005) atendiendo a las recomendaciones del Fondo Monetario Internacional para este país centroamericano.

Es evidente que cada país en vías de desarrollo presenta diferentes opciones de turismo en relación con las numerosas variables que configuran tanto su idiosincrasia como sus posibilidades reales de oferta bajo los criterios habituales de selección, diferenciación o segmentación de la industria de este sector, pero encontramos en todos ellos, con independencia de su latitud, un factor común que entronca con el cambio sufrido en las 
demandas del turismo cultural dirigido hacia estos países: la querencia del turista por vivir experiencias antes que productos y dentro de estas experiencias la identificación de aquellas que puedan ofrecer un mayor grado de singularidad y disfrute edificante para el viajero (Bringas, 2006).

Esta identificación del sector turístico actual con experiencias antes que productos presenta todo un catálogo de posibilidades y ofertas ante las que los países en vías de desarrollo tienen mucho que aportar, pues qué país no dispone de toda una tradición secular de cultura traducida en historia, costumbres diferenciales y situaciones singulares potenciales que ofrecer a un turista ávido del disfrute de ésta. Además, estos activos culturales diferentes con que cuentan los países en vías de desarrollo, frente a los que pueden ofrecer los países desarrollados, se desenvuelven a menudo en torno a los factores ya expuestos de novedad-exotismo y también compromiso solidario del viajero, quien hoy es más consciente que nunca de la necesidad de que su contribución económica vaya más allá del dinero que ha gastado en la agencia de viajes al contratar el vuelo y el hotel y se sume igualmente al desarrollo sostenible del entorno humano y medioambiental al que arriba.

Concretar el conjunto de posibles tipologías turísticoculturales que podrían albergar los países en vías de desarrollo -y que ya en algunos casos albergan- sería, sin duda, pretencioso por tratar de abarcar lo que en esencia representa la cultura en sus infinitos matices de transversalidad hacia muchos otros ámbitos de actuación turística y por la enorme diversificación actual de la propia industria del turismo. No obstante, partiendo de la clasificación hecha por Serrano, Lorenzo y López-Guzmán (2005), sí es posible enumerar, a modo de atisbo si se quiere, un listado de tipos turísticos que, con las lógicas salvedades derivadas de la situación global y el escenario real de oferta y oportunidades de cada país, estimularía la organización y explotación de los recursos culturales como fuente de riqueza y despertar de la conciencia colectiva autóctona de la necesidad de su rescate, sostenimiento y perdurabilidad (ver Tabla 1).

\begin{tabular}{|l|l|}
\hline \multicolumn{1}{|c|}{ Tipología Turística } & $\begin{array}{c}\text { Vinculaciones con la Cultura y el } \\
\text { Desarrollo }\end{array}$ \\
\hline $\begin{array}{l}\text { - Turismo de Negocios y } \\
\text { Congresos: reuniones de negocios, } \\
\text { asistencia a ferias y congresos. }\end{array}$ & $\begin{array}{l}\text { Potenciación de la gastronomía } \\
\text { local y la elaboración y venta de } \\
\text { productos tradicionales. }\end{array}$ \\
\hline
\end{tabular}




\begin{tabular}{|c|c|}
\hline \multirow{2}{*}{$\begin{array}{l}\text { - Turismo idiomático y pedagógico: } \\
\text { aprendizaje del idioma y movilidad } \\
\text { de personal docente e investigador } \\
\text { en programas interuniversitarios y } \\
\text { de cooperación internacional al } \\
\text { desarrollo. }\end{array}$} & $\begin{array}{l}\text { Visitas organizadas a recursos } \\
\text { culturales concretos. }\end{array}$ \\
\hline & $\begin{array}{l}\text { Visitas a monumentos y museos de } \\
\text { cultura autóctona. }\end{array}$ \\
\hline $\begin{array}{l}\text { - Turismo de Cruceros: conocer } \\
\text { más de un sitio en un mismo viaje. }\end{array}$ & $\begin{array}{l}\text { Visitas a actos culturales de rescate } \\
\text { del patrimonio cultural local } \\
\text { (exposiciones, representaciones } \\
\text { teatrales, conciertos de música...) }\end{array}$ \\
\hline $\begin{array}{l}\text { - Turismo de Sol y Playa: descanso, } \\
\text { buen clima, sol y playa, diversión. }\end{array}$ & $\begin{array}{l}\text { Interacción sociocultural positiva } \\
\text { entre viajeros y lugareños. }\end{array}$ \\
\hline $\begin{array}{l}\text { - Turismo Rural: conocer entornos } \\
\text { naturales y rurales, experiencias } \\
\text { extraurbanas. }\end{array}$ & $\begin{array}{l}\text { Incremento del conocimiento } \\
\text { profundo del destino; tanto para } \\
\text { visitantes como para pobladores. }\end{array}$ \\
\hline $\begin{array}{l}\text { - Turismo Deportivo: practicar } \\
\text { deportes individuales y colectivos } \\
\text { diferentes en un medio natural. }\end{array}$ & $\begin{array}{l}\text { Recuperación de las costumbres y } \\
\text { el folklore como activo cultural } \\
\text { turístico y bien patrimonial } \\
\text { autóctono. }\end{array}$ \\
\hline $\begin{array}{l}\text { - Turismo de aventura y solidaridad: } \\
\text { aventurarse por lugares recónditos, } \\
\text { realizar in situ donaciones altruistas } \\
\text { de bienes y servicios a } \\
\text { comunidades necesitadas. }\end{array}$ & \\
\hline $\begin{array}{l}\text { - Excursionismo: conocer en un } \\
\text { lapso de tiempo corto poblaciones y } \\
\text { lugares próximos al de residencia, } \\
\text { descansar, ocio y tiempo libre, } \\
\text { pasear... }\end{array}$ & $\begin{array}{l}\text { Revalorización y recuperación de } \\
\text { espacios naturales. }\end{array}$ \\
\hline
\end{tabular}

Tabla 1. Listado de tipologías turísticas de aplicación potencial en países en vías de desarrollo y sus vínculos con la cultura y el desarrollo local/nacional (adaptado de Serrano, Lorenzo y López-Guzmán, 2005)

Dentro de este listado es posible observar casos curiosos de turismo en países en vías de desarrollo amparados, por ejemplo, en la religión (entendida como manifestación cultural de los pueblos), como está ocurriendo actualmente en Cuba con el atractivo turístico de las llamadas religiones de origen africano (santería y palo-monte) (Argyriadis, 2005). Estas manifestaciones religioso-culturales procuran al turista la posibilidad de vivir en primera persona -como observador o participante- experiencias para él genuinas que difícilmente puede encontrar en su país de origen y que le transportan temporalmente a una burbuja de sensaciones irrepetibles y culturalmente multidimensionales, pues en las 
prácticas rituales se entremezclan todo tipo de elementos de naturaleza etnológica (Aguilar, 1999): lenguas antiguas, músicas tribales, escenografías con atractiva plasticidad visual, sincretismo multicultural, manifestaciones espirituales o ingesta de bebidas exóticas.

Ante todo este cúmulo de vivencias exacerbadas por la especial situación en la que se producen y por el valor añadido, para el turista, de obtenerlas en su contexto natural, éste paga por el servicio/espectáculo una cantidad que a su vez contribuirá al sostenimiento futuro de esta actividad y permitirá a la comunidad en la que se inserta el ritual mantener sus modos de vida (su cultura) y contar con un medio de subsistencia en un marco de dificultades económicas caracterizado por la consideración "en vías de desarrollo" de su país.

\section{Conclusiones}

No sería coherente apuntar desde aquí como fórmula de desarrollo para los países en vías de desarrollo el turismo cultural aislado de su contexto situacional político y sociológico. Resulta obvio que la entrada de divisas atraídas por binomio turismo-cultura en estos países sólo se puede producir si el sector percibe el destino como garante de unas condiciones suficientes de seguridad personal ante la eventual delincuencia e inestabilidad social que se da en no pocos de estos lugares, así como de higiene y salud pública.

Además, la paulatina emergencia en estos países de su oferta turístico-cultural, para que sea sostenible y redunde en beneficio directo de sus súbditos, ha de ir acompañada también de ciertas condiciones básicas de infraestructura y mano de obra cualificada que en bastantes casos son importadas, lo que dificulta la circulación del capital generado por los beneficios hacia el entorno social amplio y la creación de un tejido productivo local, autosuficiente y estable a largo plazo en este sentido.

Debido a ello, el escenario de este tipo de turismo dibuja hoy una desigual actuación en unos y otros países que hay y habrá que seguir analizando y contrastando con el fin de ayudar a establecer y proponer a los interesados la implementación de unos mínimos criterios de planificación y gestión eficiente que optimicen los recursos turístico-culturales empleados en un sector decididamente en auge en el marco de la industria turística internacional. 


\section{Bibliografía}

AA. VV. (1999). Sueños e identidades. Una aportación al debate sobre cultura y desarrollo en Europa. Barcelona: Interarts/Península.

AA. VV. (2006). Globalización. Artículo electrónico del diario El Mundo. Consultado el 15-06-2011. Disponible en http://www.elmundo.es/especiales/2001/07/sociedad/globalizacion/

Aguilar, E. (Coord.) (1999). Introducción. En Patrimonio etnológico. Nuevas perspectivas de estudio. Sevilla: Cuaderno X.

Argyriadis, K. (2005). El desarrollo del turismo religioso en La Habana y la acusación de mercantilismo. Desacatos, 18 (2005) 29-52.

Bringas, N. (2006). El turismo alternativo: una opción para el desarrollo local e dos comunidades indígenas de Baja California. Economía, sociedad y territorio, IV, 15 (2006) 551-590.

Fukuda, S. (2001). En busca de indicadores de cultura y desarrollo: avances y propuestas. En Informe mundial sobre la cultura 2000-2001 (UNESCO), 278-283. Madrid: Mundi-Prensa.

López-Guzmán, T.; Lorenzo, O.; Serrano, S. (2005). Turismo y cultura: un análisis del desarrollo económico en ciudades patrimonio de la humanidad. En J. L. Luzón et al., Actas del I Congreso Internacional de Planificación Territorial y Desarrollo Regional, 105-114. Tampico (Tamaulipas, México): Universidad Autónoma de Tamaulipas.

Lorenzo, O. (2003). Reflexiones en torno a la cultura y la educación. En L. Herrera; O. Lorenzo et al. (Coord.), Intervención Psicoeducativa: una perspectiva multidisciplinar. Granada: Grupo Editorial Universitario.

Ministerio de Industria, Turismo y Comercio (2011). Encuesta Movimientos Turísticos en Frontera (FRONTUR). Año 2010. Consultado el 18-06-2011. Disponible en:

http://www.mityc.es/esES/GabinetePrensa/NotasPrensa/2011/Paginas/npfro nturdic240111.aspx

Rivas, E. (2005). La cultura como elemento indispensable para el desarrollo. Diario La Prensa Gráfica (El Salvador). Domingo 25 de septiembre.

Serrano, S.; Lorenzo, O.; López-Guzmán, T. (2005). El turismo cultural como factor de desarrollo local: el papel de la Administración Pública. En J. L. Luzón et. al., Actas del I Congreso Internacional de Planificación Territorial y Desarrollo Regional, 94-104. Tampico (Tamaulipas, México): Universidad Autónoma de Tamaulipas.

SGAE -Sociedad General de Autores y Editores de España(2000). Informe SGAE sobre hábitos de consumo cultural. Madrid: Fundación Autor.

Venturini, E. J. (2005). Patrimonio cultural, turismo y desarrollo local: el camino de las estancias jesuíticas de Córdoba. Aportes y trasferencias, 1, 7 (2005) 45-64.

UIA (2006). Lista de Países en Vías de Desarrollo. Consultado el 18-06-2011. Disponible en: 
112 O. Lorenzo Quiles; T. López-Guzmán Guzmán; Ma C. Burgos Goye

www.uianet.org/documents/adhesion/Lista_paises_desarrollo.pdf

\author{
${ }^{1}$ Tourism and culture in developing countries \\ ${ }^{2}$ Doctor. \\ Universidad de Granada (España). \\ Email: oswaldo@ugr.es \\ ${ }^{3}$ Doctor. \\ Universidad de Córdoba (España). \\ Email: tomas.lopez@uco.es; dt1logut@uco.es \\ ${ }^{4}$ Doctor. \\ Universidad de Granada (España). \\ Email: mamengoye2000@yahoo.es
}

